\title{
YgfY Contributes to Stress Tolerance in Shewanella oneidensis Neither as an Antitoxin Nor as a Flavinylation Factor of Succinate Dehydrogenase
}

\author{
Ming-Xing Zhang ${ }^{1,2}$, Kai-Li Zheng ${ }^{1,2}$, Ai-Guo Tang ${ }^{1,2}$, Xiao-Xia Hu ${ }^{1,2}$, Xin-Xin Guo ${ }^{1,2}, \mathrm{Chao} \mathrm{Wu}^{3}$ and \\ Yuan-Yuan Cheng ${ }^{1,2, *}$ \\ 1 School of Life Sciences, Anhui University, Hefei 230602, China; zstar94@163.com (M.-X.Z.); \\ d19301054@stu.ahu.edu.cn (K.-L.Z.); d19201030@stu.ahu.edu.cn (A.-G.T.); \\ d20201038@stu.ahu.edu.cn (X.-X.H.); guoxx2017@yeah.net (X.-X.G.) \\ 2 Anhui Provincial Engineering Technology Research Center of Microorganisms and Biocatalysis, \\ Anhui University, Hefei 230602, China \\ 3 School of Resources and Environment, Anhui University, Hefei 230602, China; benny928@mail.ustc.edu.cn \\ * Correspondence: chengyy@mail.ustc.edu.cn
}

check for updates

Citation: Zhang, M.-X.; Zheng, K.-L.; Tang, A.-G.; Hu, X.-X.; Guo, X.-X.; Wu, C.; Cheng, Y.-Y. YgfY Contributes to Stress Tolerance in Shewanella oneidensis Neither as an Antitoxin Nor as a Flavinylation Factor of Succinate Dehydrogenase. Microorganisms 2021, 9, 2316. https://doi.org/10.3390/ microorganisms 9112316

Academic Editor: Siqing Liu

Received: 8 October 2021

Accepted: 2 November 2021

Published: 9 November 2021

Publisher's Note: MDPI stays neutral with regard to jurisdictional claims in published maps and institutional affiliations.

Copyright: (c) 2021 by the authors. Licensee MDPI, Basel, Switzerland. This article is an open access article distributed under the terms and conditions of the Creative Commons Attribution (CC BY) license (https:/ / creativecommons.org/licenses/by/ $4.0 /)$.
Abstract: $\mathrm{YgfY}(\mathrm{SdhE} / \mathrm{CptB})$ is highly conserved while has controversial functions in bacteria. It works as an antitoxin and composes a type IV toxin-antitoxin system with YgfX(CptA) typically in Escherichia coli, while functions as an flavinylation factor of succinate dehydrogenase and fumarate reductase typically in Serratia sp. In this study, we report the contribution of YgfY in Shewanella oneidensis MR-1 to tolerance of low temperature and nitrite. YgfY deficiency causes several growth defects of $S$. oneidensis MR-1 at low temperature, while YgfX do not cause a growth defect or morphological change of S. oneidensis MR1-1 and E. coli. YgfY do not interact with FtsZ and MreB nor with YgfX examined by bacterial two-hybrid assay. YgfY effect on growth under low temperature is not attributed to succinate dehydrogenase $(\mathrm{SDH})$ because a mutant without SDH grows comparably with the wild-type strain in the presence of succinate. The $y g f$ mutant shows impaired tolerance to nitrite. Transcription of nitrite reductase and most ribosome proteins is significantly decreased in the yof $Y$ mutant, which is consistent with the phenotypes detected above. Effects of YgfY on growth and nitrite tolerance are closely related to the RGXXE motif in YgfY. In summary, this study demonstrates pleiotropic impacts of YgfY in S. oneidensis MR-1, and sheds a light on the physiological versatility of YgfY in bacteria.

Keywords: YgfY; Shewanella; toxin-antitoxin; succinate dehydrogenase; flavinylation

\section{Introduction}

Shewanella species are emerging environmental bacteria with unique and versatile respiration, therefore playing a role in the biogeochemical cycle of metals [1,2]. In their favored niches, Shewanella species might confront stresses, such as heavy metals, toxic chemicals, high pressure and cold temperature [3]. However, the current knowledge regarding stress tolerance in the Shewanella species is still limited.

Physiological functions of bacterial toxin-antitoxin (TA) systems are commonly investigated in a number of laboratory and clinical isolates. In contrast, their physiological significance in environmental bacteria is relatively obscure. Recent studies have revealed a novel TA system in S. oneidensis MR-1 that plays a role in cell motility [4].

TA systems include a toxin protein that hinders cell growth, and an antitoxin as a protein or an RNA that protects cells from toxins via various mechanisms. Up to date, six types of TA system have been reported [5]. The type IV TA system is different from all the other TA systems in which antitoxins directly target the toxin. Instead, the antitoxin protein in type IV system protects cells from the toxin through interacting with and stabilizing the targets of the toxin. All type IV TA systems reported so far are involved 
in cell division through interfering functions of cytoskeleton proteins FtsZ and MreB. $\mathrm{CptB}(\mathrm{YgfY}) / \mathrm{CptA}(\mathrm{YgfX})$ and $\mathrm{CbtB} / \mathrm{CbtA}$ are the first two identified type IV TA systems. Both toxins of $\mathrm{CptA}$ and $\mathrm{CbtA}$ inhibit the cell division through interacting with cytoskeleton proteins, FtsZ and MreB [6,7]. CbtB antagonizes the CbtA toxicity by enhancing the bundling of cytoskeletal polymers of MreB and FtsZ in Escherichia coli [6]. YkfI and YpjF, CbtA homologous in E. coli also inhibit cell growth and lead to morphological changes of cells by interacting with FtsZ and MreB [8].

Interestingly, although highly conserved in diverse bacteria, $\mathrm{CptB}(\mathrm{YgfY})$ homologs show the other totally irrelevant activity. SdhE, a $\mathrm{CptB}(\mathrm{YgfY})$ homolog in Serratia sp. and Acetobacter pasteurianus, works as a flavinylation factor of succinate dehydrogenase (SDH) $[9,10]$. SdhE is even involved in flavinylation of fumarate reductase in Serratia sp., demonstrating the broadness of the target list of CptB/YgfY/SdhE [11].

This study aims to reveal the physiological function of $\mathrm{YgfY} / \mathrm{YgfX}$ and explores the underlying mechanism in S. oneidensis MR-1. Our results demonstrate that YgfY has pleiotropic impacts in S. oneidensis MR-1 including adaptive growth at low temperature and tolerance to nitrite. However, these impacts of YgfY were not attributed to functions as an antitoxin nor as a flavinylation factor of SDH. Lines of evidence in this study suggest a novel mechanism of YgfY function in stress tolerance of Shewanella species.

\section{Materials and Methods}

\subsection{Bacteria and Growth Conditions}

Bacterial strains were cultured in Lysogeny Broth (LB) medium or mineral medium as reported previously [12]. Strains of E. coli were cultured at $37^{\circ} \mathrm{C}$, and those of S. oneidensis MR-1 were cultured at $30^{\circ} \mathrm{C}$ or $16^{\circ} \mathrm{C}$ as indicated. Chemicals were added when needed at the following concentrations: $100 \mu \mathrm{g} / \mathrm{mL}$ diaminopimelic acid, $50 \mu \mathrm{g} / \mathrm{mL}$ kanamycin, $100 \mu \mathrm{g} / \mathrm{mL}$ ampicillin, and $20 \mu \mathrm{g} / \mathrm{mL}$ gentamycin for strains of E. coli; $10 \mu \mathrm{g} / \mathrm{mL}$ gentamycin for strains of $S$. oneidensis MR-1.

\subsection{Construction of Strains and Plasmids}

The construction of transposon library and the location of transposon insertion were conducted as described previously [13], except that S. oneidensis MR-1 was used as the parent strain of the library.

Mutants with an in-frame deletion of desired genes were constructed as described previously [14]. Briefly, flanking regions of a target gene were amplified and ligated with digested suicide vector pRE112 [15] using ClonExpress MultiS One Step Cloning Kit (Vazyme, Nanjing, China). The ligation products were transformed into E. coli SM10 and verified by PCR. Verified plasmids were extracted and transformed into E. coli WM3064 [16] and then introduced into strains of $S$. oneidensis MR-1 by conjugation. After two rounds of selection, a mutant was obtained with the deletion of a target gene and confirmed by sequencing.

For complementation, ygf $Y$ from S. oneidensis MR-1 was cloned into pBBP1 [9] using ClonExpress II One Step Cloning Kit (Vazyme, Nanjing, China). pBBP1 contains a cymA promoter that has constitutive activity and drives expression of desired genes in S. oneidensis MR-1. Generated plasmids were sequentially introduced into E. coli SM10, E. coli WM3064 and strains of $S$. oneidensis MR-1. For protein expression in E coli BL21(DE3), ygfX was cloned into pBAD24 [17] to construct pBAD_ygfX and $y g f Y$ was cloned into pET-28a(+) to construct pET_ygfY.pBAD_ygfX and pET_ygfY were co-transferred into E. coli BL21(DE3).

Site-directed mutation was conducted to construct pBBP1_ygfYG16R/E19A as described previously [13]. Briefly, primers with desired substitution at the $5^{\prime}$ ends of joint primers sites were designed and used for overlapping PCR. PCR products were ligated into digested pBBP1 using ClonExpress II One Step Cloning Kit (Vazyme, Nanjing, China). All generated plasmids were verified by sequencing before phenotype tests. All strains and plasmids used in this study were listed in Table S1 and all primers were listed in Table S2. 


\subsection{Overexpression of $Y g f Y$ and $Y g f X$ in E. coli}

E. coli BL21(DE3) bearing pBAD_ygfX and pET_ygfY was cultured in LB overnight and then diluted in fresh $\mathrm{LB}$ to 0.01 of $\mathrm{OD}_{600}$ for sub-cultivation. Inducers (isopropyl $\beta$-D-thiogalactoside (IPTG) and L-arabinose) or inhibitor (glucose) were added when subcultures grew to 0.2 of $\mathrm{OD}_{600}$. IPTG and/or L-arabinose were added to $1 \mathrm{mM}$ of final concentration to induce expression of YgfY and YgfX, alone or simultaneously. Glucose was added to $1 \mathrm{mM}$ of final concentration to suppress leaking expression both of YgfY and YgfX. Aliquots of subcultures were withdrawn to measure $\mathrm{OD}_{600}$ and observe cell morphology using a microscope Axio Scope A1 (Carl Zeiss Microscopy, LLC., New York, NY, USA).

\subsection{Bacterial Two-Hybrid Assay}

The bacterial two-hybrid system based on adenylate cyclase reconstitution in E. coli was adopted to detect the interaction of YgfX with other proteins in vivo (Euromedex, Souffelweyersheim, France). ygfX was amplified and cloned into pKNT25 and pKT25 to express a chimeric protein that fused T25 fragment of adenylate cyclase to the $\mathrm{N}$-terminal and C-terminal of YgfY, respectively. $f t s Z, m r e B$, and $y g f X$ were cloned into pUT18 and pUT18C. Detection of protein-protein interaction in vivo was conducted according to manufacturer's instruction (Euromedex, Souffelweyersheim, France). Overnight cultures of $E$. coli BTH101 bearing two plasmids were used to determine $\beta$-galactosidase activity in cells.

\subsection{RNA Isolation and Sequencing}

Overnight cultures in LB were diluted in fresh $\mathrm{LB}$ to 0.1 of $\mathrm{OD}_{600}$ and then cultivated at $16^{\circ} \mathrm{C}$ for $12 \mathrm{~h}$. Four biological replicates of subcultures were mixed and collected by centrifugation $\left(12,000 \times g, 4{ }^{\circ} \mathrm{C}, 1 \mathrm{~min}\right)$. Collected cells were subjected to extraction of total RNA using the Trizol Reagent (Takara Biotechnology, Beijing, China) according to the manufacturer's instruction. Total RNA was further purified using RNA clean kit (BioTeke, Beijing, China). The concentration, quality, and integrity of total RNA were determined using a NanoDrop spectrophotometer (Thermo Fisher Scientific, Waltham, MA, USA) and an Agilent 2100 bioanalyzer (Agilent Technologies, Waltham, CA, USA). Qualified total RNA was used to construct a sequencing library that was subsequently sequenced on a Hiseq platform (Illumina, New York, NY, USA), which was performed by Shanghai Personal Biotechnology Co., Ltd.

The data of RNA sequencing (RNA-Seq) were deposited to GOE. The accession numbers have not yet been obtained but will be provided before acceptance of this manuscript.

\section{6. qRT-PCR Assay}

cDNA was synthesized using 500 ng of qualified total RNA and PrimeScript RT reagent kit with gDNA eraser (Takara Biotechnology, Beijing, China). The qRT-PCR was conducted using the SYBR Premix Ex Taq kit (Takara Biotechnology, Beijing, China) and Lightcycler 96 (Roche, Mannheim, Germany). The gyrB was used as the reference gene. The relative expression value of target genes was obtained from three determinations with normalization against the reference gene using the method of $2^{-\Delta \Delta C t}$.

\subsection{Assay of Transcription Capability Using Click Chemistry}

To detect the transcription capability, a method of click chemistry using 5-ethynyluridine and an azide-modified fluorophore was adopted [10]. Overnight cultures of WT and $\Delta y g f Y$ were diluted into fresh $\mathrm{LB}$ to 0.01 of $\mathrm{OD}_{600}$, and then cultured at $30^{\circ} \mathrm{C}$ for $3 \mathrm{~h}$. Then, cultures were collected, concentrated for 25 folds, and added with EU (Molecular Probes, Inc., Eugene, OR, USA) to a final concentration of $0.5 \mathrm{mM}$. Cultures were allowed to grow for another $2 \mathrm{~h}$ at $30{ }^{\circ} \mathrm{C}$. After that, cells were collected, fixed with $4 \%$ formaldehyde, and neutralized with $2 \mathrm{mg} / \mathrm{mL}$ glycine. After washed with phosphate-buffered saline (PBS; $137 \mathrm{mM} \mathrm{NaCl}, 2.7 \mathrm{mM} \mathrm{KCl}, 10 \mathrm{mM} \mathrm{Na} 2 \mathrm{HPO}_{4}, 1.8 \mathrm{mM} \mathrm{KH}_{2} \mathrm{PO}_{4}, \mathrm{pH} 7.2$ ), cells were 
incubated in $0.5 \%$ Triton X-100/PBS for $10 \mathrm{~min}$. After washed with PBS, cells were stained by $2 \mu \mathrm{M}$ azide-modified Alexa Fluor 488 (Molecular Probes, Inc., Eugene, OR, USA) in Click-iT cell reaction buffer (Molecular Probes, Inc., Eugene, OR, USA) for $30 \mathrm{~min}$ at room temperature. Stained cells were washed with PBS, and then observed using a microscope Axio Scope A1 (Zeiss, Jena, Germany).

\subsection{Assay of Nitrite Tolerance}

To determine the minimal inhibition concentration (MIC) of nitrite, S. oneidensis MR-1 was cultured at $30{ }^{\circ} \mathrm{C}$ for $16 \mathrm{~h}$ and then diluted in fresh LB to 0.01 of $\mathrm{OD}_{600}$. Nitrite was added into those diluted cultures to final concentrations of 0 to $1000 \mathrm{mM}$. Diluted cultures were cultivated at $30{ }^{\circ} \mathrm{C}$ for $24 \mathrm{~h}$.

The nitrite tolerance of $\Delta y g f Y$ and wild-type (WT) was determined by plating nitritetreated cells on LB agar plates and counting colony-forming units (CFU). In detail, strains were cultured in $\mathrm{LB}$ at $30{ }^{\circ} \mathrm{C}$ for $16 \mathrm{~h}$ and then diluted in fresh LB to 0.01 of $\mathrm{OD}_{600}$. Diluted cultures were subcultivated to $0.2-0.3$ of $\mathrm{OD}_{600}$ before nitrite of $470 \mathrm{mM}(15 \times \mathrm{MIC})$ was added. At indicated time points, aliquots of nitrite-treated subcultures were withdrawn, washed with $0.9 \% \mathrm{NaCl}$ two times to remove remained nitrite. Washed cultures were serially diluted in $0.9 \% \mathrm{NaCl}$ and spotted on LB agar plates. Cells on plates were cultivated at $30^{\circ} \mathrm{C}$ for $24 \mathrm{~h}$ before counting CFU.

\subsection{Assay of Tolerance to Heat Shock}

Strains were cultured in LB at $30^{\circ} \mathrm{C}$ for $16 \mathrm{~h}$ and then diluted in fresh LB to 0.01 of $\mathrm{OD}_{600}$. Diluted cultures were subcultivated to $0.2-0.3$ of $\mathrm{OD}_{600}$ at $30^{\circ} \mathrm{C}$, and then incubated at $42{ }^{\circ} \mathrm{C}$. At indicated time points, aliquots of heat-shocked subcultures were withdrawn, diluted with $0.9 \% \mathrm{NaCl}$, and spotted on LB agar plates. If needed, $100 \mathrm{U} / \mu \mathrm{L}$ catalase solution of $5 \mu \mathrm{L}$ was overlayed on culture spots. Cells on plates were cultivated at $30{ }^{\circ} \mathrm{C}$ for $24 \mathrm{~h}$ before counting CFU.

\subsection{Quantification of Succinate}

Strains were cultured in LB overnight. Cells were collected by centrifugation $(3000 \times g$, $10 \mathrm{~min}$ ) for $1 \mathrm{~min}$ and washed three times with a mineral medium (MM) [12]. After that, cells were resuspended in MM containing $10 \mathrm{mM}$ succinate to final density of 2.5 of $\mathrm{OD}_{600}$. These cultures were incubated at $30{ }^{\circ} \mathrm{C}$ with vigorous shaking, and aliquots were withdrawn at indicated time points. Aliquots of samples were centrifugated at $12,000 \times g$ for $10 \mathrm{~min}$ and treated with $0.22 \mu \mathrm{m}$ filters. Succinate remained in MM was quantified using Agilent 1260 liquid chromatography (Agilent Technologies Inc., Santa Clara, CA, USA) equipped with an Aminex HPX-87H column (Bio-Rad Laboratories, Inc., Hercules, CA, USA). $\mathrm{H}_{2} \mathrm{SO}_{4}$ of $5 \mathrm{mM}$ was used as a running buffer at a flow rate of $0.5 \mathrm{~mL} / \mathrm{min}$. The standard calibration curve of succinate was obtained using MM containing succinate over range of $1-50 \mathrm{mM}$.

\section{Results}

\subsection{YgfY Is Required for Normal Growth of S. oneidensis MR-1}

A transposon library of $S$. oneidensis MR-1 was constructed to screen genes that contribute to tolerance to various stresses. We accidently found a colony showing smaller size than WT (data not shown). The transposon in this mutant inserted into a putative two-gene operon containing $y g f Y$ (SO_1339) and $y g f X\left(S_{1}{ }_{1} 1340\right)$. The $y g f Y$ and $y g f X$ are predicted as an operon coding a type IV TA system, in which $y g f Y$ encodes an antitoxin and $y g f X$ encodes a toxin.

To confirm the effect of YgfY and YgfX on cell growth, mutants with in-frame deletion of $y g f X$ and $y g f Y$ were constructed. Intriguingly, we also successfully constructed a $y g f Y$ mutant that is theoretically inaccessible if YgfY was a cognate antitoxin of YgfX. $\Delta y g f Y$ and $\Delta y g f Y X$ rather than $\Delta y g f X$ showed defect in growth at $30^{\circ} \mathrm{C}$ (Figure S1). $\Delta y g f Y$ and $\Delta y g f Y X$ showed more severe defect of growth when cultivated at $16^{\circ} \mathrm{C}$ (Figure 1A). Growth was 
quantified by the optimal density of cultures at $600 \mathrm{~nm}$ that could be affected by the cell density as well as the cell size. The cell density of cultures was further determined by counting colony forming units (CFU). After cultivated at $16^{\circ} \mathrm{C}$ for $48 \mathrm{~h}$, cultures of $\Delta y g f Y$ reached to $(2.02 \pm 0.30) \times 10^{9} \mathrm{CFU} / \mathrm{mL}$ and those of WT reached to $(3.62 \pm 0.15) \times 10^{9} \mathrm{CFU} / \mathrm{mL}$. The CFU of $\Delta y g f Y$ cultures was about $56 \%$ of those of WT, which was consistent with the result of optimal density measurement. Meanwhile, cells in these cultures were observed by microscopy, and no morphological difference was observed among $\Delta y g f Y, \Delta y g f X, \Delta y g f Y X$ and WT (Figure S2). Complementation of $y g f Y$ completely restored the growth of $\Delta y g f Y$ and $\Delta y g f Y$ to a similar level of WT (Figure 1B). Expression of $y g f Y$ from its native promoter also restored the growth of $\Delta y g f Y$ and $\Delta y g f Y X$ to a similar level of WT (Figure S3).
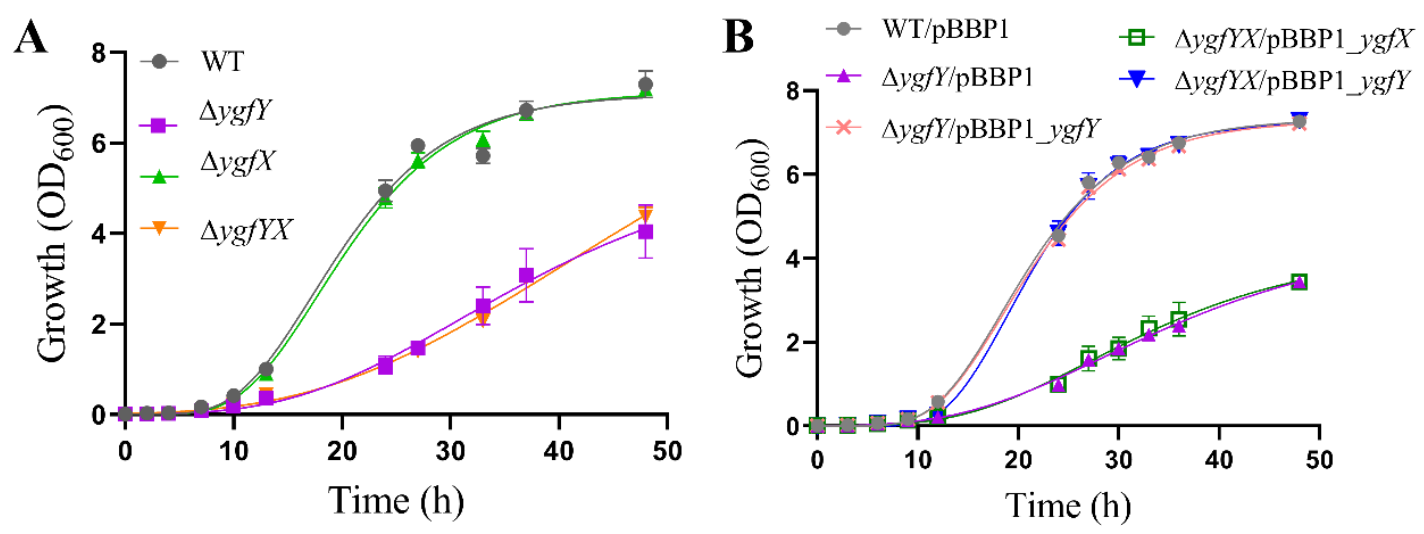

Figure 1. YgfY but not YgfX affected growth of S. oneidensis MR-1. (A) Growth of WT and mutants. (B) Complementation of YgfY by expressing it from a constitutive promoter in pBBP1. All strains were cultured in LB at $16{ }^{\circ} \mathrm{C}$ under aerobic condition. The data are the mean $\pm \mathrm{SD}(n=3)$. Error bars for some data points were too small to be shown.

These results indicated that YgfY rather than YgfX positively affected the growth and did not support $\mathrm{YgfY} / \mathrm{YgfX}$ in S. oneidensis MR-1 as a TA system, because $\Delta y g f X X$ lacking both $\mathrm{YgfY}$ and $\mathrm{YgfX}$ should show growth recovery compared with $\Delta y g f Y$ if $Y g f X$ functions as a toxin and $\mathrm{YgfY}$ as a cognate antitoxin.

\section{2. $Y g f Y$ and $Y g f X$ Do Not Fulfil the Criteria of Type IV TA System}

Both $y g f Y$ and $y g f X$ are supposed to compose a two-gene operon in which the start codon of $y g f Y$ is $37 \mathrm{bp}$ away from the stop codon of $y g f X$ (Figure 2A). The RT-PCR detected the transcription of the intergenic region between $y g f Y$ and $y g f X$, indicating that they belong to the same operon (Figure 2B). The similarity of amino acid sequences between YgfY homologs in S. oneidensis MR-1 and E. coli MG1655 was 62.5\%, and that between YgfX homologs in two strains was $34.8 \%$. EMBOSS Needle was used to analyze the similarity of amino acid sequences.

Hetero-expression of toxins in E. coli commonly causes growth defect. To further examine physiological function of $\mathrm{YgfY}$ and $\mathrm{YgfX}$, they were overexpressed in E. coli BL21(DE3). Expression of YgfY was driven by an IPTG-induced promoter in pET-28a(+) and that of YgfX was driven by an arabinose-induced promoter in pBAD24. As the blank controls, cultures of E. coli BL21(DE3) in the early exponential phase was added with $1 \mathrm{mM}$ glucose as an inhibitor to minimize leaking expression of YgfY and YgfX. After addition of inducers or glucose for $4 \mathrm{~h}$, cultures expressing either YgfX or YgfY showed growth defect, and those expressing both YgfX and YgfX showed a more severe growth defect compared with the glucose-added cultures (Figure 3A). This result did not support YgfX and YgfY functioning as a toxin and cognate antitoxin, respectively. Otherwise, expression of YgfY should rescue the growth defect caused by YgfX expression. Many proteins become toxic when highly overexpressed as published previously [18], which probably explains the growth defect observed upon overexpression of YgfX or YgfY. Overexpression of toxin YgfX (CptA) from E. coli in its native host causes change of cell morphology to the lemon 
shape [7]. Therefore, the cell morphology of E. coli BL21(DE3) after expressing YgfY and/or YgfX was observed. No morphological change was observed for cells expressing YgfX or YgfY or both (Figure 3B). No phenotype was observed in corresponding deletion mutants and overexpression strains, showing that $\mathrm{YgfY}$ and $\mathrm{YgfX}$ did not follow one of criteria of the type IV TA system.
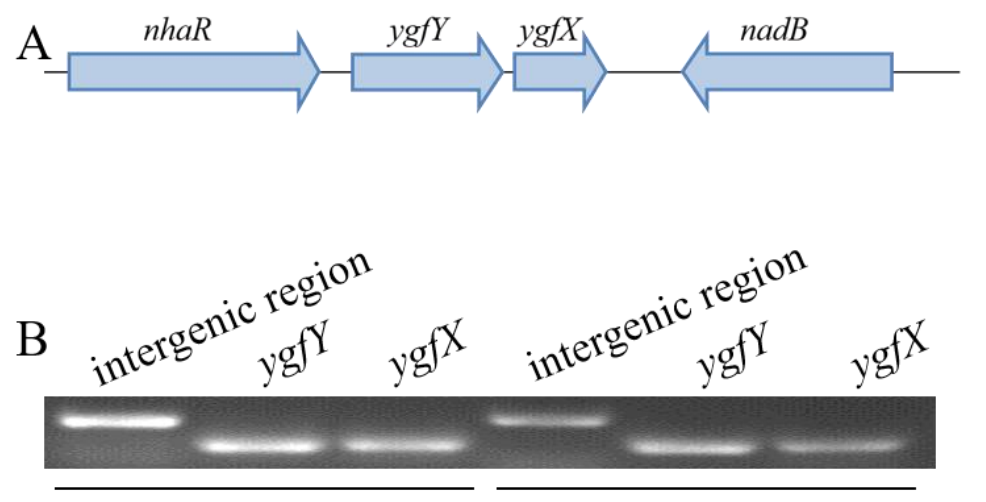

\section{Genomic DNA}

cDNA

Figure 2. The $y g f Y$ located in an operon with $y g f X$. (A) Schematic of arrangement of $y g f Y, y g f X$ and their neighbor genes in genome of S. oneidensis MR-1. (B) Transcription of $y g f Y$ and $y g f X$ and intergenic region between them.

B Time (h)
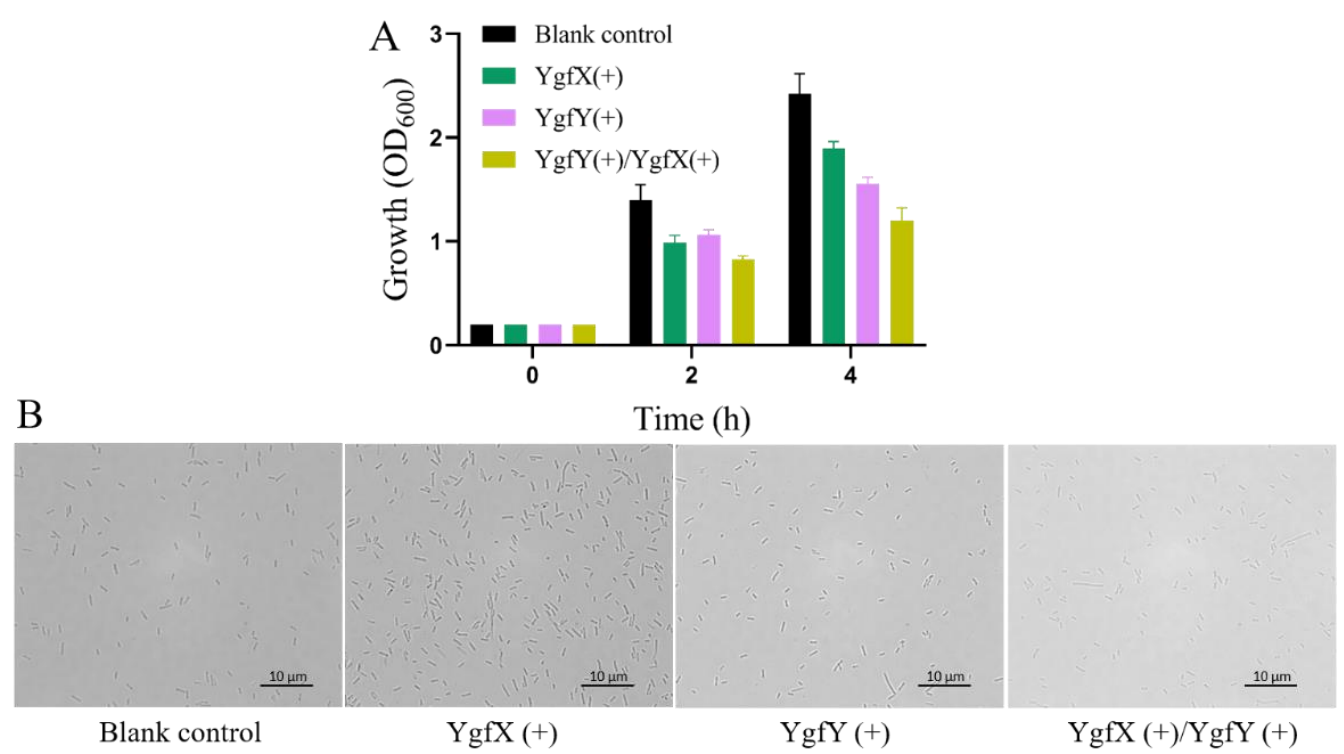

Figure 3. Hetero-expression of YgfY in E. coli BL21(DE3). (A) Growth of E. coli BL21(DE3) expressing YgfY and/or YgfX under induction. Cultures of E. coli BL21 bearing pBAD24_ygfX and pET_ygfY were grown to early exponential phase before the addition of inducers or glucose. The data are the mean \pm SD $(n=3)$. (B) Cell morphology observed after induction for $4 \mathrm{~h}$.

YgfX (CptA) in E. coli hinders cell division through interacting with cytoskeleton proteins, FtsZ and MreB [7]. CbtA, the toxin in another type VI TA system, also interacts with FtsZ and MreB to hinder division of E. coli cells [6]. The interaction of YgfX with FtsZ and MreB was examined using bacterial two hybridization system. Compared to the negative and positive controls, no obvious interaction was detected either between YgfX and FtsZ nor between YgfX and MreB (Figure 4A,B). In addition, no interaction between YgfY and YgfX was detected (Figure 4C). 

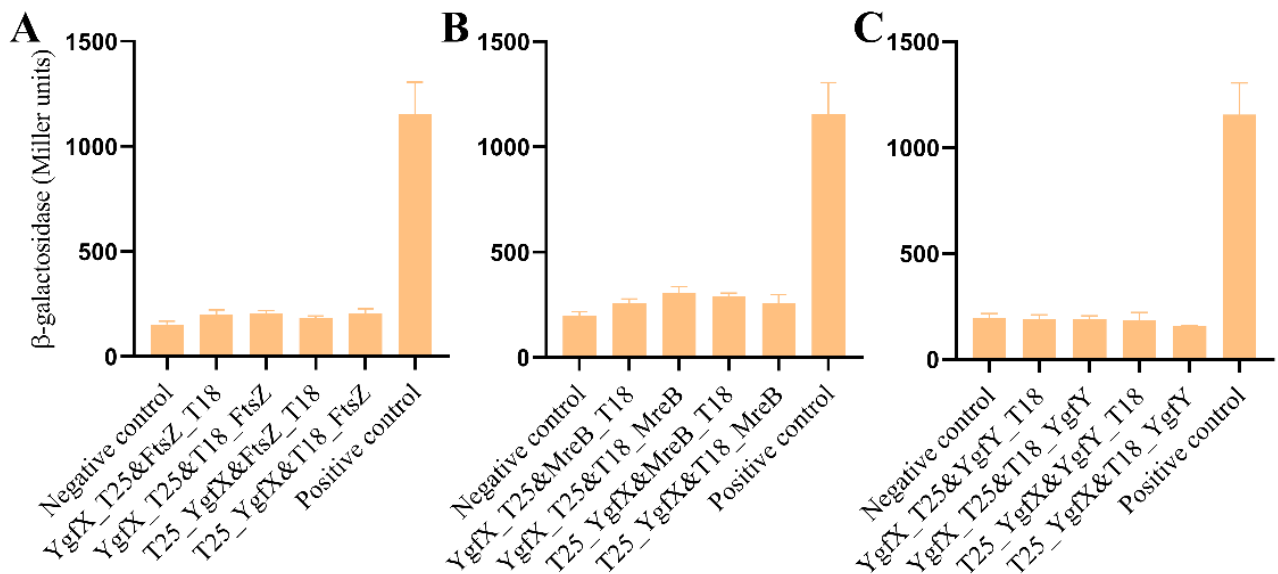

Figure 4. YgfX did not interact with (A) MreB, (B) FtsZ, and (C) YgfY. E. coli BTH101 expressing YgfX and the other protein simultaneously was examined for $\beta$-galactosidase activity in cells. The data are the mean $\pm \mathrm{SD}(n=3)$.

\subsection{Ygf $Y$ Does Not Attribute to Succinate Catabolism}

YgfY in S. oneidensis MR-1 shares $60.2 \%$ similarity with its homolog SdhE in Serratia sp. SdhE in Serratia sp. functions as a flavinylation factor of SDH and fumarate reductase $[11,19]$. We examined whether growth defect of $\Delta y g f Y$ was attributed to succinate metabolism. S. oneidensis MR-1 encodes SDH and can consume succinate. However, it cannot use succinate as a sole carbon source to support growth [20]. Therefore, we first compared the growth of $\Delta y g f Y, \Delta s d h$ and WT in the mineral medium supplemented with lactate and succinate. Lactate was added as a carbon source. There was no obvious difference in growth between $\Delta s d h$ and WT, while $\Delta y g f Y$ showed a growth defect compared with $\mathrm{WT}$ in the mineral medium (Figure 5A). Then, we examined succinate consumption by resting cells in the mineral medium. After incubation for $12 \mathrm{~h}, \Delta y g f Y$ showed a comparable ability to consume succinate with WT, while $\Delta s d h E$ showed an obvious defect in succinate consumption (Figure 5B).

A

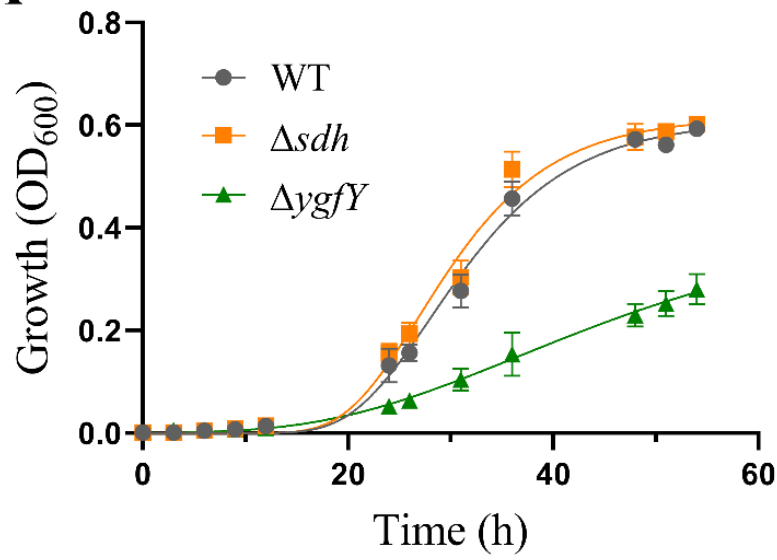

B

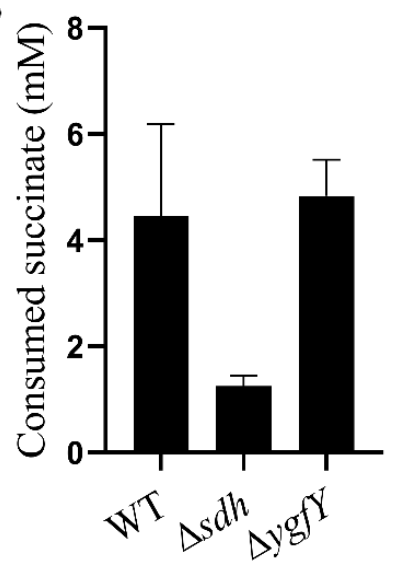

Figure 5. YgfY did not involve in succinate metabolism. (A) Growth in the mineral medium with $50 \mathrm{mM}$ lactate and $10 \mathrm{mM}$ succinate. (B) Succinate consumption by resting cells for $12 \mathrm{~h}$ in the mineral medium containing $10 \mathrm{mM}$ succinate. The data are the mean $\pm \operatorname{SD}(n=3)$. Error bars for some data points were too small to be shown.

SdhE in Serratia sp. possesses an RGXXE motif that is essential for its activity. SdhE variants with substitution mutation of G16R or E19A in RGXXE motif are nonfunctional [19]. YgfY in S. oneidensis MR-1 also possess this motif (Figure 6A). Surprisingly, the RGXXE motif 
is highly conserved in SDH flavinylation factor in diverse organisms such as Saccharomyces cerevisiae, Arabidopsis thaliana and Homo sapiens. Mutation of G in the RGXXE motif of this factor is closely related to hereditary paraganglioma [21]. Therefore, we examined whether the RGXXE motif is also essential for the activity of YgfY in S. oneidensis MR-1. A YgfY mutant ( $\left.\mathrm{YgfY} \mathrm{Y}^{\mathrm{G} 16 \mathrm{R} / \mathrm{E} 19 \mathrm{~A}}\right)$ was constructed with substitution of glycine and glutamic acid in RGXXE motif by arginine and alanine, respectively. YgfYG16R/E19A was readily expressed in $\Delta y g f Y$ (Figure S3), while did not rescue the growth defect of $\Delta y g f Y$ (Figure 6B). These results confirmed that RGXXE motif was also essential for the activity of YgfY in S. oneidensis MR-1. These results indicated that the growth effect of YgfY should attribute to other activity rather than SDH flavinylation.

A

Q8EH90|Shewanella G4V4G2 Serratia P64559|Escherichia Q9FI44|Arabidopsis Q9NA72|Caenorhabditis Q4V5I9 Drosophila Q9NX18 Homo Q8C6I2|Mus Q08230 Saccharomyces A0A319DIJ2|Aspergillus

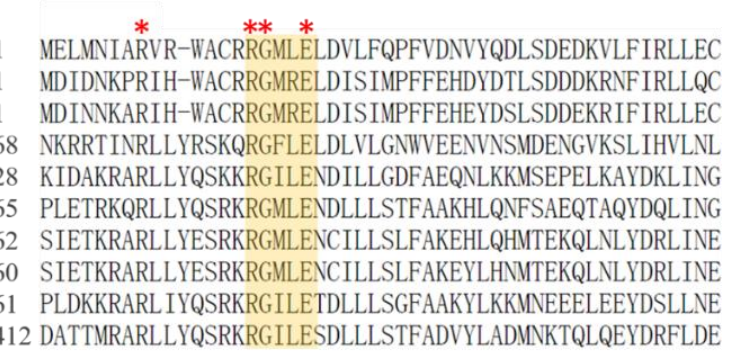

B

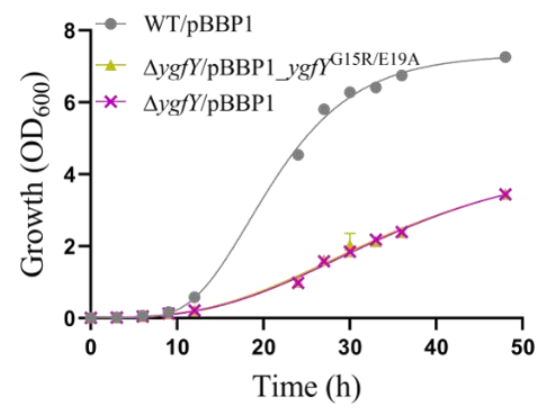

Figure 6. Conserved sites essential for YgfY activity. (A) Amino acid alignment of succinate dehydrogenase flavinylation factors and YgfY homologs. Entry of proteins in Uniport and family of organisms are indicated. Red asterisk $\left(^{*}\right)$ indicate conserved amino acid residues and RGXXE motif is highlighted with a yellow box. (B) Growth of $\Delta y g f Y$ complemented with YgfY mutant (YgfYG16R/E19A $)$. The data are the mean $\pm \operatorname{SD}(n=3)$. Error bars for some data points were too small to be shown.

\subsection{YgfY Contributes to Capability of Transcription and Translation in S. oneidensis MR-1}

To explore the underlying mechanism of YgfY effect on growth in S. oneidensis MR-1, the transcriptomes of $\Delta y g f Y$ and WT were compared. $\Delta y g f Y$ and WT were cultured to the early exponential phase and subjected to analysis of RNA sequencing. Some housekeeping genes involved in transcription, translation, cell wall synthesis, and cell division were down-regulated (Table S3) in $\Delta y g f Y$. Among them, genes encoding ribosome proteins were noticeable. Fifty out of fifty-four genes for ribosome proteins were down-regulated for more than two folds (Table S3). The result of qRT-PCR confirmed the decrease in transcription of representative genes (Figure 7). The rate of ribosome formation is an integral part of the regulation of cell growth [22]. The decreased transcription of ribosome proteins in $\Delta y g f Y$ is consistent with growth defect of this mutant.

The transcription capability of $\Delta y g f Y$ was compared with WT using EU-based click chemistry [10]. EU is an uracil analog, and is incorporated into nascent RNA after addition. A weaker signal was detected in $\triangle y g f Y$ than in WT after addition of EU for $2 \mathrm{~h}$ (Figure 8), indicating that the transcription capability was impaired in $\Delta y g f Y$.

Then, the translation capacity was compared by examining the tolerance to lethal stresses that cause global protein misfolding. Previous research reports that bactericidal aminoglycosides cause mistranslation, misfolding and aggregation of nascent proteins, which correlates to reactive oxygen species (ROS)A production and consequent cell death [23,24]. Inhibitors of protein synthesis, such as chloramphenicol, block ROS-related death of bacterial cells stressed by bactericidal antibiotics [25]. Therefore, we reasoned that if YgfY deficiency causes the lowered capacity of translation, $\Delta y g f Y$ should show an increase in the tolerance to these stresses. The heat shock causes protein misfolding and aggregation [26], and there is a numerical correlation between the protein denature and the death of bacterial cells after the heat shock [27]. Consistent with our presumption, $\Delta y g f Y$ showed an increased tolerance to heat killing than WT (Figure 9A). Moreover, catalase 
supplementation to quench ROS greatly improved the survival rate of WT, while not so much for that of $\Delta y g f($ (Figure 9B).

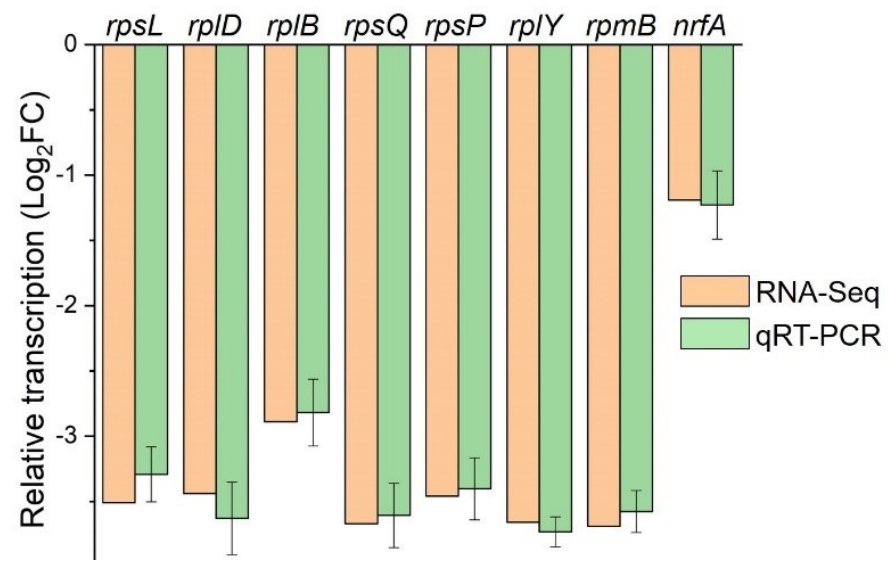

Figure 7. Transcription of representative genes that were down-regulated in $\Delta y g f Y . \Delta y g f Y$ and WT were cultured at $16{ }^{\circ} \mathrm{C}$ for $12 \mathrm{~h}$ for transcriptome analysis (RAN-Seq). Transcription (log2(fold change)) of genes was examined using qRT-PCR and compared with RNA-seq data. Error bars indicate standard deviations of results from three biological replicates.

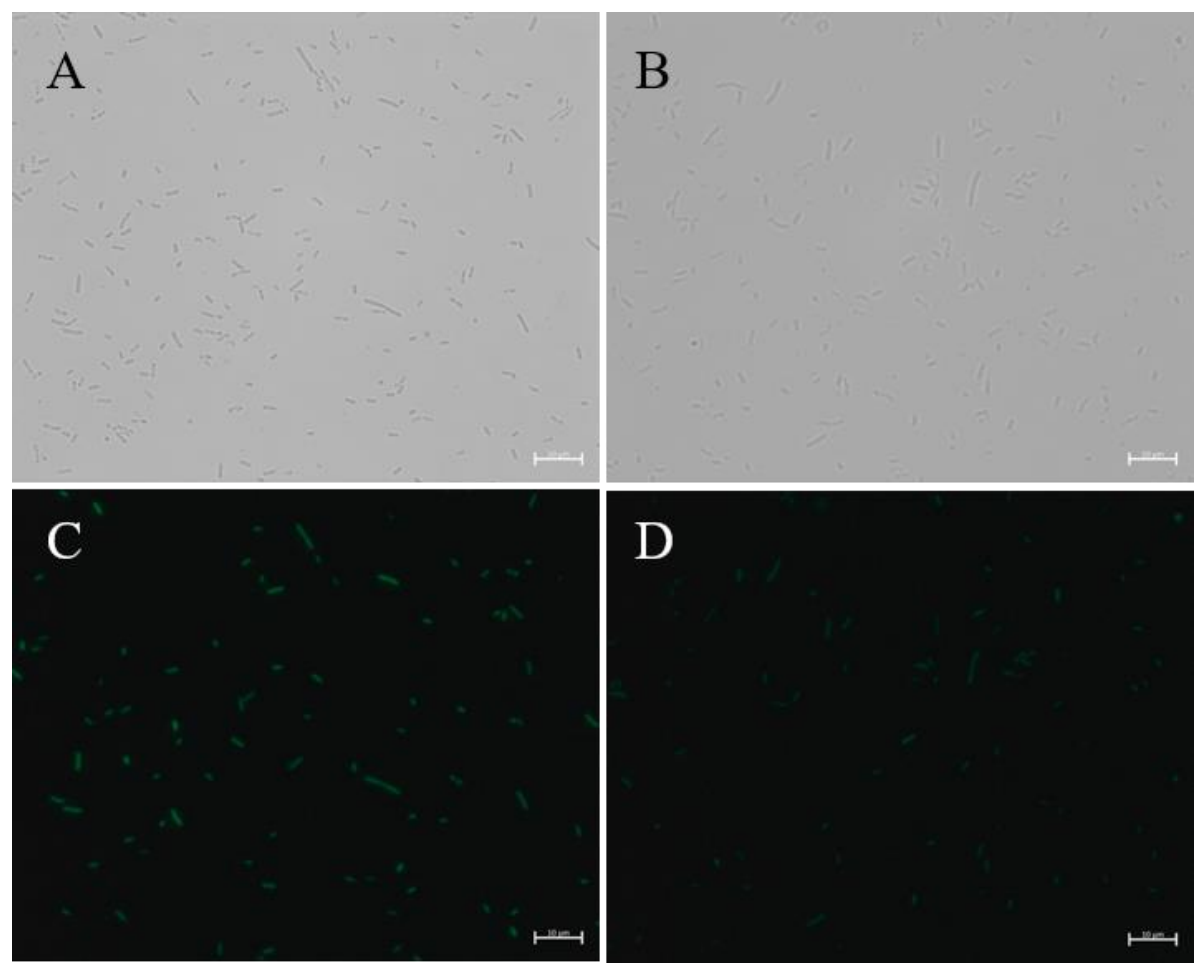

Figure 8. RNA synthesis in WT and $\Delta y g Y$. Cultures at the early exponential phase were exposed to EU. Nascent RNA incorporated with EU was detected by azide-modified Alexa Fluor 488 under a microscope. (A,C) Shows cells of WT under brightfield and fluorescence. (B,D) Shows cells of $\Delta y g f Y$ under brightfield and fluorescence. The experiments were repeated three times and similar results were observed. 

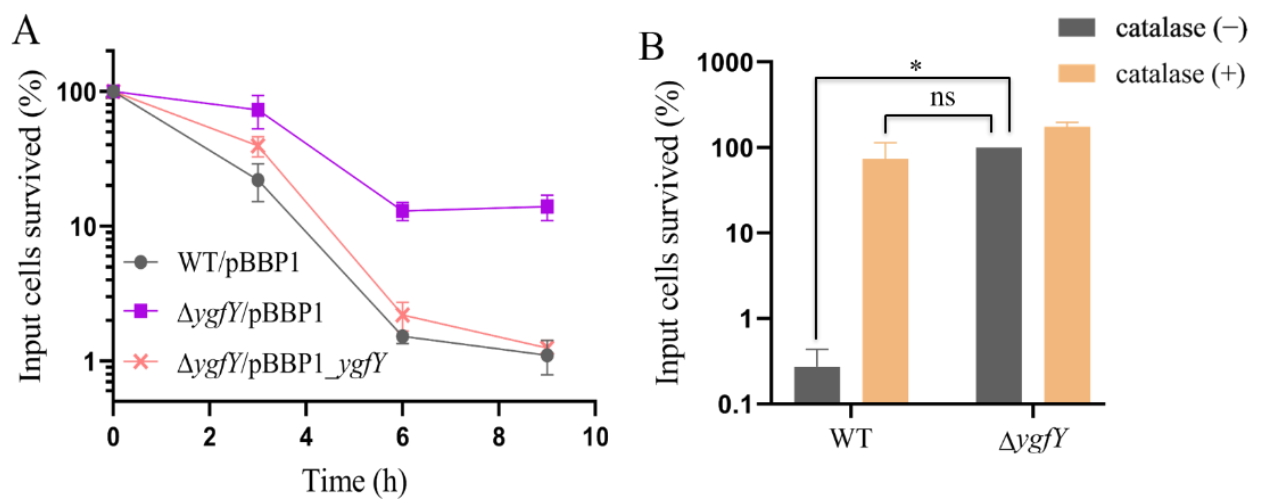

Figure 9. Survival of cells after exposed to heat shock of $42{ }^{\circ} \mathrm{C}$. (A) Colony forming units (CFU) of cultures grown on LB plates. (B) CFU of cultures incubated in $42{ }^{\circ} \mathrm{C}$ for $6 \mathrm{~h}$ and then cultured on LB plates with or without catalase overlayed. Error bars indicate standard deviations of results from three biological replicates. Percentage of survived cells are normalized by CFU in cultures before heat exposure $(0 \mathrm{~h})$. Asterisk indicates significant difference and ns indicates no significant difference.

In addition to house-keeping genes, transcription of some functional genes was also changed, such as two genes ( $n r f A$ and $n s r R)$ involved in nitrite reduction. Transcription of $n r f A$ and $n s r R$ were down-regulated in $\Delta y g f Y$ (Table S3), which was also confirmed by qRT-PCR (Figure 6). The nitrite tolerance of $\Delta y g f Y$ was examined next. When exposed to nitrite at a concentration of $15 \times \mathrm{MIC}, \Delta y g f Y$ showed significantly more impaired tolerance to nitrite than WT, and the impairment was readily reversed by expression of YgfY but not YgfYG16R/E19A (Figure 10).

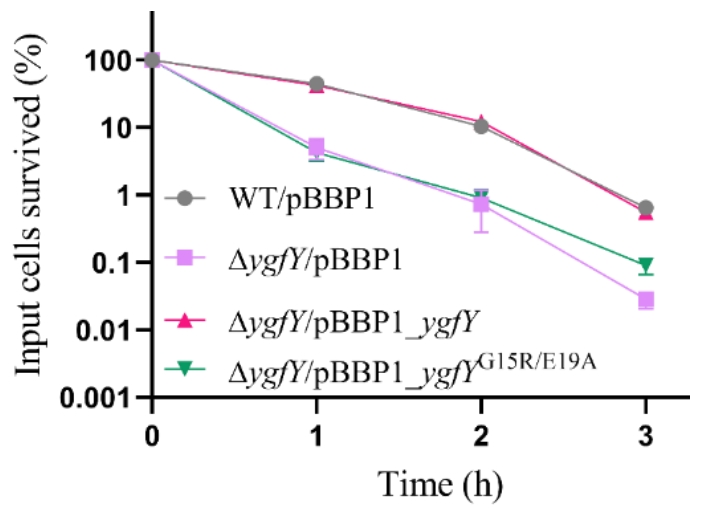

Figure 10. Nitrite tolerance of S. oneidensis MR-1. Cultures were exposed to $470 \mathrm{mM}$ of nitrite for indicated time and then spotted on LB plates for cultivation and counting survived cells based on CFU. Percentage of survived cells are normalized by CFU in cultures before nitrite exposure $(0 \mathrm{~h})$. The data are the mean $\pm \operatorname{SD}(n=3)$.

\section{Discussion}

YgfXY homologs in E. coli and Acinetobacter baumannii were previously found to form a type IV TA system pair, which could not be confirmed later in Serratia sp. by different groups $[28,29]$. Similarly, we are unable to reproduce the toxic activity of YgfXY homologs in S. oneidensis MR-1. On the other hand, YgfY homologs in E. coli, Serratia sp. and Acetobacter pasteurianus show the activity as assembly factor for flavinylation of $\mathrm{SDH}[30,31]$. In this study, we reveal that YgfY has pleiotropic impacts in physiology of $S$. oneidensis MR-1, but neither as an antitoxin nor as a flavinylation factor of SDH.

Genome annotation proposes YgfY and YgfX in S. oneidensis MR-1 as a TA system presumably for two reasons: (i) YgfY shares high similarity with the antitoxin CptB in E. coli, and (ii) $y g f Y$ locates adjacent to and in front of $y g f X$ in the genome, which might 
compose a two-gene operon. Antitoxin CptB and toxin CptA in E. coli compose a type IV TA system in which CptA hinders cell division and causes the morphological change of cells through interacting with FtsZ and MreB, while CptB antagonizes CptA through stabilizing FtsZ and MreB [7]. Interaction of CptB with FtsZ and MreB causes morphological change of E. coli cells. Although YgfY and YgfX are co-transcribed and deficiency of YgfY causes growth defect of $S$. oneidensis MR-1 (Figure 1), other lines of evidence did not support that YgfY and YgfX function as a type IV TA system. Firstly, $\Delta y g f Y X$, deficient of both YgfX and YgfY, shows the same growth defect as $\Delta y g f Y$ (Figure 1). If YgfX functioned as a toxin and was antagonized by $Y g f Y$, deletion of $y g f X$ in $\Delta y g f Y$ should rescue the growth defect of $\Delta y g f Y$. Secondly, overexpression of $Y g f X$ in E. coli does not cause morphological change of cells (Figure 3). Thirdly, YgfX does not interact with FtsZ or MtrB (Figure 4). Overall, YgfY and YgfX do not fulfill the criteria of a type IV TA system.

The severe growth defect of $\Delta y g f Y$ also cannot be attributed to SDH because $\Delta s d h$ shows an unimpaired growth (Figure 5), although interaction between YgfY and SDH cannot be excluded. $\Delta y g f Y$ shows a global change in transcriptome compared with WT (Figure 6, Table S3). It is very unlikely that YgfY directly regulates transcription for the absence of any known DNA-binding motifs. Hence, transcriptome change for YgfY deficiency is more likely a feedback regulation of cells through other signals and regulators. Interestingly, SdhE in Serratia sp. also demonstrates pleiotropic impacts. Except for inability to use succinate, a mutant of Serratia sp. without $s d h E$ shows a decrease in the transcription of an operon responding to synthesize an antibiotic prodigiosin [30], which is also hardly to be explained by SdhE functioning as a flavinylation factor of SDH.

Results from site mutation of YgfY provides some hints about the mechanism underlying pleiotropic impacts of YgfY. YgfY possesses a conserved RGXXE motif in flavinylation factor of SDH that is surprisingly conserved in all three kingdoms (Figure 5). Mutation of G16 in RGXXE motif abolishes the in vivo activity of YgfY in S. oneidensis MR-1 (Figures 5 and 7). Structure investigations show that Gly in the RGXXE motif of the flavinylation factor of SDH plays the exact same role in all investigated organisms crossing three kingdoms. Gly in RGXXE motif forms a critical hydrogen with SdhA in SDH in E. coli and humans [32,33]. Moreover, Gly in RGXXE of SdhE(CptB) can also form a hydrogen bond with FrdA in the fumarate reductase complex and is indispensable for FrdA flavinylation in E. coli [34]. Based on those investigations, we propose that YgfY likely functions as a flavinylation factor as do its homologs in diverse organisms, while it has unidentified targets that eventually impose effects on growth and nitrite tolerance. Identification of those targets are on the way to deepen our view of this family of flavinylation factors.

Supplementary Materials: The following are available online at https:/ / www.mdpi.com/article/ 10.3390 / microorganisms9112316/s1, Figure S1: Growth of $\Delta y g f$ and WT at $30^{\circ} \mathrm{C}$, Figure S2: Cell morphology of $\Delta y g f Y, \Delta y g f X, \Delta y g f Y X$ and WT. Stains were cultured in LB at $16{ }^{\circ} \mathrm{C}$ for $48 \mathrm{~h}$ and subjected to observation under a microscope, Figure S3: YgfY expressed from its native promoter revered the growth defect of $\Delta y g f Y$. Region containing $y g f Y$ coding sequence and $285 \mathrm{bp}$ upstream was cloned into pBBP1MCS5 to express $y g f Y$ from its native promoter. Resulted plasmid pBBR1_ygfY was then transformed into strains of Shewanella. Strains transformed with the empty vector pBBP1MCS5 were set as controls. The data are the mean \pm SD $(n=3)$, Table S1: Strains and plasmids used in this study, Table S2: Primers used in this study, Table S3: Genes differentially expressed and discussed in this study.

Author Contributions: Conceptualization, Y.-Y.C.; methodology, Y.-Y.C., C.W., M.-X.Z., K.-L.Z., A.-G.T., X.-X.H. and X.-X.G.; software, M.-X.Z., K.-L.Z., A.-G.T., X.-X.H., X.-X.G. and C.W.; validation, M.-X.Z., K.-L.Z., A.-G.T., X.-X.H., X.-X.G. and Y.-Y.C.; formal analysis, M.-X.Z., K.-L.Z., A.-G.T., X.-X.H., X.-X.G. and Y.-Y.C.; investigation, Y.-Y.C.; resources, Y.-Y.C. and C.W.; data curation, X.-X.H.; writing-original draft preparation, Y.-Y.C.; writing—review and editing, Y.-Y.C.; visualization, Y.Y.C.; supervision, Y.-Y.C.; project administration, Y.-Y.C. and C.W.; funding acquisition, Y.-Y.C. and C.W. All authors have read and agreed to the published version of the manuscript. 
Funding: This research was funded by the National Natural Science Foundation of China, grant number 31770139 and 32170135, the Science Foundation for the Excellent Youth Scholars of Anhui Province of China, grant number 2108085Y10, and the Open Fund for Discipline Construction of Institute of Physical Science and Information Technology, Anhui University, grant number S01003121.

Data Availability Statement: The data supporting the findings of this study are available within the article.

Conflicts of Interest: The authors declare no conflict of interest.

\section{References}

1. Heidelberg, J.F.; Paulsen, I.T.; Nelson, K.E.; Gaidos, E.J.; Nelson, W.C.; Read, T.D.; Eisen, J.A.; Seshadri, R.; Ward, N.; Methe, B.; et al. Genome sequence of the dissimilatory metal ion-reducing bacterium Shewanella oneidensis. Nat. Biotechnol. 2002, 20, 1118-1123. [CrossRef] [PubMed]

2. Tiedje, J.M. Shewanella-The environmentally versatile genome. Nat. Biotechnol. 2002, 20, 1093-1094. [CrossRef]

3. Li, B.B.; Cheng, Y.Y.; Fan, Y.Y.; Liu, D.F.; Fang, C.Y.; Wu, C.; Li, W.W.; Yang, Z.C.; Yu, H.Q. Estimates of abundance and diversity of Shewanella genus in natural and engineered aqueous environments with newly designed primers. Sci. Total Environ. 2018, 637-638, 926-933. [CrossRef] [PubMed]

4. Yao, J.; Zhen, X.; Tang, K.; Liu, T.; Xu, X.; Chen, Z.; Guo, Y.; Liu, X.; Wood, T.K.; Ouyang, S.; et al. Novel polyadenylylationdependent neutralization mechanism of the HEPN/MNT toxin/antitoxin system. Nucleic Acids Res. 2020, 48, 11054-11067. [CrossRef] [PubMed]

5. Harms, A.; Brodersen, D.E.; Mitarai, N.; Gerdes, K. Toxins, Targets, and Triggers: An Overview of Toxin-Antitoxin Biology. Mol. Cell 2018, 70, 768-784. [CrossRef]

6. Masuda, H.; Tan, Q.; Awano, N.; Wu, K.P.; Inouye, M. YeeU enhances the bundling of cytoskeletal polymers of MreB and FtsZ, antagonizing the CbtA (YeeV) toxicity in Escherichia coli. Mol. Microbiol. 2012, 84, 979-989. [CrossRef]

7. Masuda, H.; Tan, Q.; Awano, N.; Yamaguchi, Y.; Inouye, M. A novel membrane-bound toxin for cell division, CptA (YgfX), inhibits polymerization of cytoskeleton proteins, FtsZ and MreB, in Escherichia coli. FEMS Microbiol. Lett. 2012, 328, 174-181. [CrossRef] [PubMed]

8. Wen, Z.; Wang, P.; Sun, C.; Guo, Y.; Wang, X. Interaction of Type IV Toxin/Antitoxin Systems in Cryptic Prophages of Escherichia coli K-12. Toxins 2017, 9, 77. [CrossRef]

9. McNeil, M.B.; Hampton, H.G.; Hards, K.J.; Watson, B.N.J.; Cook, G.M.; Fineran, P.C. The succinate dehydrogenase assembly factor, SdhE, is required for the flavinylation and activation of fumarate reductase in bacteria. FEBS Lett. 2014, 588, 414-421. [CrossRef]

10. Cheng, Y.Y.; Wang, W.J.; Ding, S.T.; Zhang, M.X.; Tang, A.G.; Zhang, L.; Li, D.B.; Li, B.B.; Deng, G.Z.; Wu, C. Pyruvate accelerates palladium reduction by regulating catabolism and electron transfer pathway in Shewanella oneidensis. Appl. Environ. Microbiol. 2021, 87, e02716-20. [CrossRef]

11. Cheng, Y.Y.; Wu, C.; Wu, J.Y.; Jia, H.L.; Wang, M.Y.; Wang, H.Y.; Zou, S.M.; Sun, R.R.; Jia, R.; Xiao, Y.Z. FlrA Represses Transcription of the Biofilm-Associated bpfA Operon in Shewanella putrefaciens. Appl. Environ. Microbiol. 2017, 83, e02410-16. [CrossRef] [PubMed]

12. Wu, C.; Cheng, Y.Y.; Yin, H.; Song, X.N.; Li, W.W.; Zhou, X.X.; Zhao, L.P.; Tian, L.J.; Han, J.C.; Yu, H.Q. Oxygen promotes biofilm formation of Shewanella putrefaciens CN32 through a diguanylate cyclase and an adhesin. Sci. Rep. 2013, 3, 1945. [CrossRef]

13. Xiong, J.; Chan, D.; Guo, X.; Chang, F.; Chen, M.; Wang, Q.; Song, X.; Wu, C. Hydrogen production driven by formate oxidation in Shewanella oneidensis MR-1. Appl. Microbiol. Biotechnol. 2020, 104, 5579-5591. [CrossRef] [PubMed]

14. Jao, C.Y.; Salic, A. Exploring RNA transcription and turnover in vivo by using click chemistry. Proc. Natl. Acad. Sci. USA 2008, 105, 15779-15784. [CrossRef]

15. Edwards, R.A.; Keller, L.H.; Schifferli, D.M. Improved allelic exchange vectors and their use to analyze 987P fimbria gene expression. Gene 1998, 207, 149-157. [CrossRef]

16. Dehio, C.; Meyer, M. Maintenance of broad-host-range incompatibility group P and group Q plasmids and transposition of Tn5 in Bartonella henselae following conjugal plasmid transfer from Escherichia coli. J. Bacteriol. 1997, 179, 538-540. [CrossRef] [PubMed]

17. Guzman, L.M.; Belin, D.; Carson, M.J.; Beckwith, J. Tight regulation, modulation, and high-level expression by vectors containing the arabinose PBAD promoter. J. Bacteriol. 1995, 177, 4121-4130. [CrossRef] [PubMed]

18. Vazquez-Laslop, N.; Lee, H.; Neyfakh, A.A. Increased persistence in Escherichia coli caused by controlled expression of toxins or other unrelated proteins. J. Bacteriol. 2006, 188, 3494-3497. [CrossRef] [PubMed]

19. McNeil, M.B.; Fineran, P.C. The Conserved RGxxE Motif of the Bacterial FAD Assembly Factor SdhE Is Required for Succinate Dehydrogenase Flavinylation and Activity. Biochemistry 2013, 52, 7628-7640. [CrossRef]

20. Yang, Y.; McCue, L.A.; Parsons, A.B.; Feng, S.; Zhou, J. The tricarboxylic acid cycle in Shewanella oneidensis is independent of Fur and RyhB control. BMC Microbiol. 2010, 10, 264. [CrossRef] [PubMed]

21. Hao, H.X.; Khalimonchuk, O.; Schraders, M.; Dephoure, N.; Bayley, J.P.; Kunst, H.; Devilee, P.; Cremers, C.W.; Schiffman, J.D.; Bentz, B.G.; et al. SDH5, a gene required for flavination of succinate dehydrogenase, is mutated in paraganglioma. Science 2009, 325, 1139-1142. [CrossRef] [PubMed] 
22. Lindahl, L.; Zengel, J.M. Expression of ribosomal genes in bacteria. Adv. Genet. 1982, 21, 53-121. [CrossRef] [PubMed]

23. Kohanski, M.A.; Dwyer, D.J.; Wierzbowski, J.; Cottarel, G.; Collins, J.J. Mistranslation of membrane proteins and two-component system activation trigger antibiotic-mediated cell death. Cell 2008, 135, 679-690. [CrossRef] [PubMed]

24. Ling, J.; Cho, C.; Guo, L.T.; Aerni, H.R.; Rinehart, J.; Soll, D. Protein aggregation caused by aminoglycoside action is prevented by a hydrogen peroxide scavenger. Mol. Cell 2012, 48, 713-722. [CrossRef] [PubMed]

25. Luan, G.; Hong, Y.; Drlica, K.; Zhao, X. Suppression of Reactive Oxygen Species Accumulation Accounts for Paradoxical Bacterial Survival at High Quinolone Concentration. Antimicrob. Agents Chemother. 2018, 62, e01622-17. [CrossRef] [PubMed]

26. Richter, K.; Haslbeck, M.; Buchner, J. The heat shock response: Life on the verge of death. Mol. Cell 2010, 40, 253-266. [CrossRef] [PubMed]

27. Rosenberg, B.; Kemeny, G.; Switzer, R.C.; Hamilton, T.C. Quantitative evidence for protein denaturation as the cause of thermal death. Nature 1971, 232, 471-473. [CrossRef] [PubMed]

28. ElBanna, S.A.; Moneib, N.A.; Aziz, R.K.; Samir, R. Genomics-guided identification of a conserved CptBA-like toxin-antitoxin system in Acinetobacter baumannii. J. Adv. Res. 2021, 30, 159-170. [CrossRef]

29. McNeil, M.B.; Iglesias-Cans, M.C.; Clulow, J.S.; Fineran, P.C. YgfX (CptA) is a multimeric membrane protein that interacts with the succinate dehydrogenase assembly factor SdhE (YgfY). Microbiology 2013, 159, 1352-1365. [CrossRef] [PubMed]

30. Mcneil, M.B.; Clulow, J.S.; Wilf, N.M.; Salmond, G.P.C.; Fineran, P.C. SdhE Is a Conserved Protein Required for Flavinylation of Succinate Dehydrogenase in Bacteria. J. Biol. Chem. 2012, 287, 18418-18428. [CrossRef] [PubMed]

31. Kiefler, I.; Bringer, S.; Bott, M. SdhE-dependent formation of a functional Acetobacter pasteurianus succinate dehydrogenase in Gluconobacter oxydans-A first step toward a complete tricarboxylic acid cycle. Appl. Microbiol. Biot. 2015, 99, 9147-9160. [CrossRef] [PubMed]

32. Maher, M.J.; Herath, A.S.; Udagedara, S.R.; Dougan, D.A.; Truscott, K.N. Crystal structure of bacterial succinate:quinone oxidoreductase flavoprotein SdhA in complex with its assembly factor SdhE. Proc. Natl. Acad. Sci. USA 2018, 115, $2982-2987$. [CrossRef] [PubMed]

33. Sharma, P.; Maklashina, E.; Cecchini, G.; Iverson, T.M. The roles of SDHAF2 and dicarboxylate in covalent flavinylation of SDHA, the human complex II flavoprotein. Proc. Natl. Acad. Sci. USA 2020, 117, 23548-23556. [CrossRef]

34. Sharma, P.; Maklashina, E.; Cecchini, G.; Iverson, T.M. Crystal structure of an assembly intermediate of respiratory Complex II. Nat. Commun. 2018, 9, 274. [CrossRef] [PubMed] 